magnitude, and the other a blue 9. The contrast of colours was very striking, but there was little difference in size. In a letter recently received from the Rev. Mr. Webb, I find that it was previously observed by him, and it appears as one of his own discoveries in the second edition of "Celestial Objects," published in 1868 . The red star is there classed as $6.5 \mathrm{mag}$. and the blue as 8 . The two stars, therefore, appeared to differ very considerably in magnitude when seen by Mr. Webb, while to me, eleven years subsequently, they seemed quite nearly equal. Hence I conclude that the red is a variable, and I wish to call the attention of observers to it while it still remains in view. By a rough measurement $\mathrm{I}$ make out its position for $188 \mathrm{I}=a$ 7 h. Iom. 44s., and $\delta-23^{\circ} 6^{\prime} 6$. JOHN Birmingham.

Millbrook, Tuam, April 9

\section{Concealed Bridging Convolutions in a Human Brain}

In his wo:k on the "Convolutions of the Human Brain" Ecker denies explicitly that the first and second external bridging convolutions of Gratiolet, as seen in Cercopithecus, Inuus, \&c., are ever concealed, either in the higher apes or in foetal or adult man. I have however in my possession an adult human brain in which $a$ convolution nearly corresponding in position to the external bridging one of Gratiolet is concealed, while another slightly external to it is nearly so. The brain was hardened in nitric acid with the membranes on (a much preferable method, by the by, to that of first removing the membranes; as these, by absorbing the acid and swelling, serve, like so many wedges, to keep the convolutions apart, and prevent the shrinkage that otherwise takes place). There was no indication of any concealed convolution until the membranes, just moistened for the purpose with water, were being removed. Then, owing to the opening out of the sulcus occipitalis transversus of Ecker, the tip of one became visible, and this tip, even now that the edges of the sulcus are widely separated, is from one-eighth to one sixth of an inch beneath the general surface.

Its position relative to the great longitudinal fissure and to the posterior border of the gyrus supramarginalis seems to me pretty accurately to correspond to that of the external bridging convoIution to those parts in the brain of an Indian pig-tailed baboon of undetermined species with which I have compared it ; but in the latter the sulcus occipitalis transversus does not exist, while in this human brain, as is very common, the lateral or horizontal portion of the fissura parieto occipitalis, beneath the bevelled edge of which in the baboon the convolution lies concealed, has a very short course indeed.

The only difference then is that in the one specimen (the human) the concealed convolution lies in the transverse occipital fissure, there being no lateral extension of the parieto-occipital fissure, while in the other it lies in the parieto-occipital fissure, the transverse fissure not existing WILLIAM CARTER

Liverposl, March 26

\section{Sound of the Aurora}

IF I had consulted Franklin's account of his Polar researches before I sent you my extract from Tacitus, I should not have revived the question of sounds being heard with the aurora borealis. Franklin and his companions watched the aurora 343 times in two successive winter seasons; and never once, he says, did they observe a sound. Were, then, the experiences quoted by your other correspondent and myself mere illusions? Perhaps not. Franllin made bis observations at and about the southern shore of Bear Lake, in latitudes varying from $67^{\circ}$ to $69^{\circ}$ north ; might not the greater volume of air through which the phenomenon had to pass in reaching our island have caused the electric fluid to work up a sound? Surely that is possible The attractive force of the aurora is-we learn from Franklin himself-increased within a certain limit as its rays proceed southwards; for whereas Parry and his party at Port Bowen in latitude $73^{\circ} 15^{\prime}$ noticed no deflection of the compass-needle under the influence of coruscations, Franklin and his party on the shores of the Bear Lake, six degrees further south, constantly observed thi; effect. And the attractive force is strongly felt here-hindering telegraphic communication at all events. Might not the vibratory force not sensible at within so short a distance from its origin as the attraction be increased within a greater limit?

Sumymead, Chislehurst Common

\section{PERIODIC OSCILLATIONS OF BAROMETRIC PRESSURE}

THE MSS. of the accompanying article, which was left unfinished by the late Mr. John Allan Broun, F.R.S., were handed over to me some time ago by Prof. Balfour Stewart, with a request that I would put them into shape for publication.

I have not found it necessary to make manyalterations in, or additions to the original, and where made they are mostly indicated in initialed foot-notes.

\section{E. Douglas Archibald}

In an article which appeared in NATURE (vol. xix. p. 6) a remarkable relation was shown to exist between the annual ranges of the atmospheric pressure and of the temperature of the air, as derived from the monthly means obtained from several years' observations of the barometer and thermometer at certain stations in India. The results and the conclusions from them do not appear to have been always understood, and as they bear on some of the most interésting questions on meteorology, I shall now examine them anew with the aid of observations at some other stations, under different local conditions.

For this end it is desirable to employ some elementary considerations. Let us, first of all, consider the action of varying temperature on a vertical column of the atmosphere. Let us consider a column of air reaching from the soil at $B$ to the upper limit of the atmosphere at $A$; and suppose that the pressure shown by a barometer at $\mathrm{B}$ is 30 inches, while at a higher station, c, it is only 20 inches. If, now, the column of air is heated so that the temperature of the part $\mathrm{BC}$ is increased by $10^{\circ} \mathrm{F}$. we know from laboratory experiments that the air will expand, so that a part of that which was below $\mathrm{C}$ will be pushed above it, and while the barometer at $\mathrm{B}$ will continue to show 30 inches, that at $\mathrm{C}$ will show $20^{\circ}$ inches, the mercury at $\mathrm{C}$ will have risen two-tenths of an inch.

If, now, we suppose that the mass of air remains constant throughout the year, there will be an annual variation of the barometer at $\mathrm{c}$, where its height will be greatest in the warmest month and lowest in the coldest month. For the same reason the difference of the barometric heights at $\mathrm{B}$ and $\mathrm{C}$ will be least in the warmest month and greatest in the coldest.

It has been supposed that the mass of the atmosphere remains constant throughout the year; if this is not the case the variations of pressure at $\mathrm{C}$ will not depend on temperature alone, but also on the other causes which produce variations at $\mathrm{B}$.

In NATURE, vol, xx. p. 55, Mr. Douglas Archibald has given a series of differences of barometric heights at high and low stations in India for the months from October to April. The month of lowest mean temperature, January, shows always, as in the case just supposed, the greatest difference of pressures. As the high and low station is never in the same vertical, the one being sometimes 300 miles horizontally distant from the other, it is difficult to eliminate the part of the variation due to temperature at the higher station, but if we take as an approximation, however rude, the mean of the temperatures at the two stations as that of the vertical column, we can see that a considerable part of the variation at the upper station may be due to the expansion of the column with temperature.

Thus for Leh and Lahore the mean temperatures and difference of barometric heights are ${ }^{1}$ :-

I The numbers are taken from the work cited by Mr. Archibald, "The Indian Meteorologist's V'ade Mecum," by Mr. H. F. Blanford, Pt. ii. pp. I76, 178 . 